\title{
Dissociative Dysphonia in Delusional Disorder
}

\author{
Dr. Mithun S. ${ }^{1}, \&$ Dr. Hanock Nischal ${ }^{2}$ \\ ${ }^{1}$ Assistant Professor, Department of Psychiatry, Srinivas Institute of Medical Sciences\& \\ Research Centre, Mangalore, India \\ ${ }^{2}$ Assistant Professor, Department of ENT, Srinivas Institute of Medical Sciences\& Research \\ Centre, Mangalore, India \\ E-mail: mdmitsmj@gmail.com
}

Type of the Paper: Case Report

Type of Review: Peer Reviewed.

Indexed In: OpenAIRE.

DOI: http://doi.org/10.5281/zenodo.1462590.

Google Scholar Citation: IJHSP

\section{How to Cite this Paper:}

Mithun, S. \& Hanock Nischal. (2018). Dissociative Dysphonia in Delusional Disorder. International Journal of Health Sciences and Pharmacy (IJHSP), 2(2), 7-10. DOI: http://doi.org/10.5281/zenodo.1462590.

International Journal of Health Sciences and Pharmacy (IJHSP)

A Refereed International Journal of Srinivas University, India.

(C) With Authors.

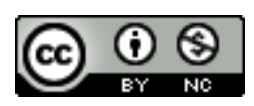

This work is licensed under a Creative Commons Attribution-Non Commercial 4.0 International License subject to proper citation to the publication source of the work.

Disclaimer: The scholarly papers as reviewed and published by the Srinivas Publications (S.P.), India are the views and opinions of their respective authors and are not the views or opinions of the SP. The SP disclaims of any harm or loss caused due to the published content to any party. 


\title{
Dissociative Dysphonia in Delusional Disorder
}

\author{
Dr. Mithun S. ${ }^{1}$, \& Dr. Hanock Nischal ${ }^{2}$ \\ ${ }^{1}$ Assistant Professor, Department of Psychiatry, Srinivas Institute of Medical Sciences\& \\ Research Centre, Mangalore, India \\ ${ }^{2}$ Assistant Professor, Department of ENT, Srinivas Institute of Medical Sciences\& Research \\ Centre, Mangalore, India \\ E-mail:mdmitsmj@gmail.com
}

\begin{abstract}
Dissociative dysphonia is less commonly seen in general population. Previous literature has focussed on interplay of dysphonia mainly in schizophrenia or schizoaffective disorders. Here we discuss a unique case of delusional disorder with dissociative dysphonia. The challenges in the evaluation and management are discussed.
\end{abstract}

Keywords: Dissociation, Dysphonia, Delusional disorder.

\section{INTRODUCTION :}

Functional dysphonia(FD) refers to the loss of voice not accounted by anatomical or neurological pathology and which apparently appears secondary to psychological processes [1]. Amidst the debate over the terminology of $\mathrm{FD}$, it can be replaced by muscle tension dysphonia(MTD) which further has 3 etiological subgroups namely psychological, vocal misuse/abuse and compensatory [2]. Dysphonia due to psychological causes has been included in dissociative motor disorders (F44.4) in International Classification of Diseases- $10^{\text {th }}$ revision - clinical descriptions and diagnostic guidelines(ICD-10-CDDG) [3].Here we discuss a case of dissociative dysphonia in a patient with delusional disorder.

\section{CASE DETAILS :}

A 45 year old married lady,illiterate,from a rural background, residing with her husband and son; was on treatment for chronic obstructive pulmonary disease with no other medical co-morbidities. She presented to Ear Nose Throat(ENT) outpatient clinic with an acute onset episode of inability to talk in the last 2 days with no other neurological deficits. ENT surgeon evaluated her with indirect laryngoscopy and opined that apart from minimal congestion, her vocal cords approximated adequately. On finding that her symptoms could not be explained by her examination findings, the patient was then referred to the psychiatry department.

In the psychiatry outpatient clinic interview husband and son reported that from past 3 years they have observed her to be fearful about being harmed by her neighbours. However, this concern was not accounted for by rest of the family members and tried convincing about the same but the patient continued to have such beliefs. Patient had stopped going out of the house and minimised visitors at home. Patient had even emphasised multiple times on changing the residence and shifting out due to such fears. In addition, the attendees reported that from past 6 months she used to be worried about the same, often crying about it, refusing to eat food and disturbed sleep at nights. However, her selfcare and occupational functioning of doing household chores were adequate. On interviewing the patient, she was tearful and whispering inaudible words with gestures, thus further mental status examination was not possible.

The need for admission was explained but the family refused and opted for out-patient treatment. She was provisionally diagnosed with a delusional disorder of 3 years duration with depressive symptoms of 6 months duration.Brief psychoeducation of the nature and prognosis of illness to the patient and family was done. Patient was started on Tab. Olanzapine $5 \mathrm{mg}$ at night, Tab Escitalopram 
10mg in the morning, Tab Clonazepam 0.25 mg morning and night and was advised for frequent visits. On follow up after 5 days, her speech output was better with audible words. At the end of 1 week,her dysphonia had subsided and was then subjected to detailed evaluation.

On assessment,3 years history of delusions of persecution and misinterpretation along with depressive symptoms were evident with no other psychopathology noted. She received the primary diagnosis of delusional disorder(F22.0)with the comorbid dissociative motor disorder(F44.4)as per (ICD-10). Patient was then seen frequently over next 1 month, during which her medications were optimised to olanzapine $10 \mathrm{mg}$ and escitalopram $10 \mathrm{mg}$ while clonazepam was tapered and stopped. Patient improved significantly wherein her acting out behaviour on the delusions had subsided however her insight remained poor.Psycho education to family, regular compliance and working on her insight were the targets on her future visits.

\section{DISCUSSION :}

Although amidst the dissociative motor symptoms, dysphonia is a common symptom [4], [5], the overall prevalence of dissociative dysphonia in general population is less ranging from $0.4 \%$ to $0.98 \%$ [6]. Dissociative comorbidity is seen in $5 \%$ to $30 \%$ with major psychiatric disorders [7], however, the interplay between dissociative and psychotic disorders are limited to case reports and mainly to schizophrenia or schizoaffective disorder [8].

During the relapse of psychotic symptoms, exacerbation of dissociation occurs [9] and when psychosis subsides with antipsychotics dissociation tends to improve. As seen in our patient her psychotic symptoms and dysphonia improved significantly over a week of treatment. Escitalopram was given because depression is the commonest comorbidity seen in delusional disorder and antidepressants like selective serotonin reuptake inhibitors(SSRI's) are required [10].Along with the pharmacological treatment, psychoeducationto the family and patient about the delusional disorder and behavioural management of dissociation is of equal importance in the follow-up visits.

\section{CONCLUSION :}

This is a unique case of dissociative dysphonia in a patient with the delusional disorder as most of the literature earlier has not focussed on the interplay between these two disorders. Dissociation in the form of dysphonia can pose a potential challenge in terms of evaluation and management.Prompt referral and regular follow up helped in relieving the distress in the patient with a treatment plan in place for her future visits.

\section{REFERENCES :}

[1] Murphy RA, Hallahan B. Psychosis improved dysphonia. BMJ Case Rep [Internet]. 2013 Dec 7 [cited 2018 Sep 28];2013. Available from: https://www.ncbi.nlm.nih.gov/pmc/article s/PMC3863058/

[2] Behlau M, Madazio G, Oliveira G. Functional dysphonia: strategies to improve patient outcomes. Patient Relat Outcome Meas. 2015 Dec 1;6:243-53.

[3] Organization WH, WHO. The ICD-10 Classification of Mental and Behavioural Disorders: Clinical Descriptions and Diagnostic Guidelines. World Health Organization; 1992. 377 p.

[4] Owens C, Dein S. Conversion disorder: the modern hysteria. Adv Psychiatr Treat. 2006;12(2):152-157.

[5]Stefánsson JG, Messina JA, Meyerowitz S. Hysterical neurosis, conversion type: clinical and epidemiological considerations. Acta Psychiatr Scand. 1976 Feb;53(2):119-38.

[6] Prevalence and causes of dysphonia in a large treatment-seeking population Cohen - 2012 - The Laryngoscope Wiley Online Library [Internet]. [cited 2018 Sep 29]. Available from: https://onlinelibrary.wiley.com/doi/abs/10 .1002/lary.22426.

[7] Foote B, Smolin Y, Kaplan M, Legatt ME, Lipschitz D. Prevalence of dissociative disorders in psychiatric outpatients. Am J Psychiatry. 2006;163(4):623-629.

[8] Kilcommons AM, Morrison AP. Relationships between trauma and psychosis: an exploration of cognitive and 
dissociative factors. Acta Psychiatr Scand. 2005;112(5):351-359.

[9] Spitzer C, Haug HJ, Freyberger HJ. Dissociative symptoms in schizophrenic patients with positive and negative symptoms. Psychopathology.
1997;30(2):67-75.

[10] Manschreck TC., Khan NL. Recent Advances in the Treatment of Delusional Disorder. Can J Psychiatry. 2006 Feb 1;51(2):114-9. 